\title{
Images in Hepatology
}

\section{Liver Space Occupying Lesion in a Patient with Secondary Immunodeficiency}

\author{
Piyush Ranjan, Mandhir Kumar, Rinkesh Bansal, Munish Sachdeva \\ Department of Gastroenterology, Sir Ganga Ram Hospital, New Delhi, India
}

A 46-year-old female presented with significant weight loss and low grade fever of 2 months duration. She had cholecystectomy one year back. Ultrasonography abdomen revealed large mass in right lobe of liver. Complete blood count was and peripheral smear were normal. Her hepatitis B virus antigen (HBsAg) and antibody to hepatitis C virus (anti-HCV) were nonreactive. Human immunodeficiency virus (HIV) serology was positive. Subsequently, CT angiography of abdomen was done which revealed a large heterogenous mass of $7 \mathrm{~cm} \times 5.8 \mathrm{~cm}$ in segment 4 and 5 of liver infiltrating gall-bladder fossa (Figure 1A \& B). CA 19.9 and AFP were normal. Her CD $4+$ counts was $43 / \mu l$ and HIV RNA was $1,90,000 / \mu \mathrm{l}$.

Ultrasound guided biopsy from liver mass revealed nonHodgkin's Lymphoma (NHL), diffuse large B cell (Figure 2) and positive CD 20 staining (Figure 3). CT chest and bone marrow aspirate was done; both were normal. She was started on highly activated anti-retroviral therapy (HAART) i.e. tenofovir, emtricitabine and efavirenz along with R-CHOP (rituximab, cyclophosphamide, doxorubicin, vincristine and prednisone).

NHL in acquired immunodeficiency syndrome (AIDS) is a late manifestation of disease, most often associated with CD4+ < 100, though can occur at any CD4+ count. ${ }^{1}$ Whereas secondary involvement of the liver by NHL is relatively common, involving liver in as many as $21 \%$ of advanced NHL cases, primary hepatic lymphoma is extremely rare. NHL associated with AIDS involves primarily extranodal sites, especially the digestive tract and the central nervous system. Primary hepatic lymphoma is an uncommon neoplasm among these patients. ${ }^{2}$ Lei et al proposed diagnostic criteria for $\mathrm{PHL}^{3}$ (i) the symptoms are mainly caused by liver involvement at presentation, (ii) distant lymphadenopathy is neither palpable

Keywords: immunodeficiency, NHL, PHL

Received: 21.5.2013; Accepted: 9.7.2013; Available online: 8.8.2013

Address for correspondence: Piyush Ranjan, Department of Gastroenterology, Sir Ganga Ram Hospital, New Delhi, India.

E-mails: pranjan2020@sify.com; piyushranjan70@gmail.com

Abbreviations: HBsAg: hepatitis B virus antigen; $\mathrm{HCV}$ : hepatitis $\mathrm{C}$ virus; HIV: human immunodeficiency virus; AIDS: acquired immunodeficiency syndrome

http://dx.doi.org/10.1016/j.jceh.2013.07.002
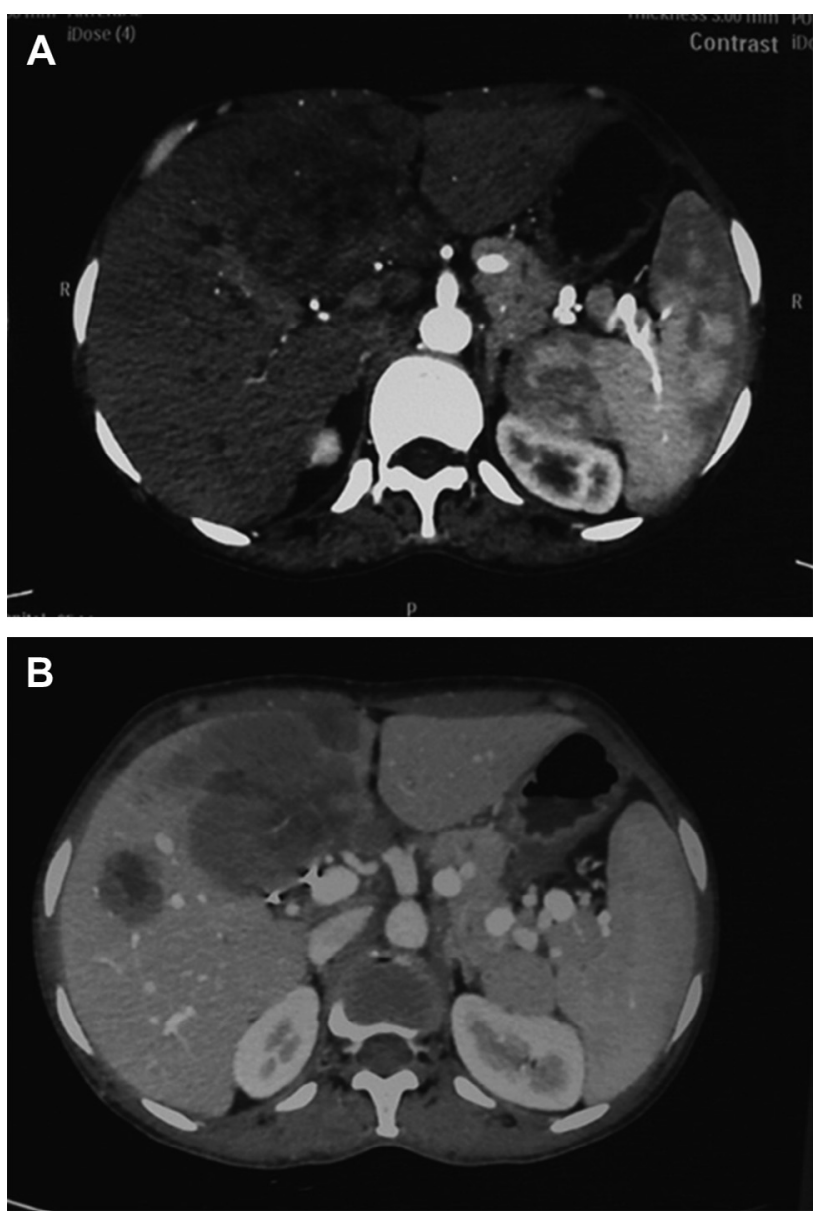

Figure $1 \mathrm{~A}$ : Arterial phase of triphasic CT showing infiltrating lesion in segment 4 \& 5 . There is no enhancement in arterial phase. B: Venous phase of Triphasic CT showing infiltrating lesion in segment 4 \& 5 . There is no contrast uptake in venous phase.

clinically at presentation or detected during radiological staging studies and (iii) no leukemic blood picture is observed on the peripheral blood film. Diffuse large B cell lymphoma is the commonest histological type of PHL as was seen in this patient. Incidence of all AIDSrelated lymphomas has declined since the use of HAART. Still with better control of opportunistic infections, PHL is a common AIDS-defining illness. There are many histologic types of primary hepatic lymphoma however diffuse large B cell lymphoma is most common type. Chemotherapy with RCHOP regimen is treatment of choice. ${ }^{4}$ $\mathrm{PHL}$ is an aggressive disease with poor response to therapy and survival. 


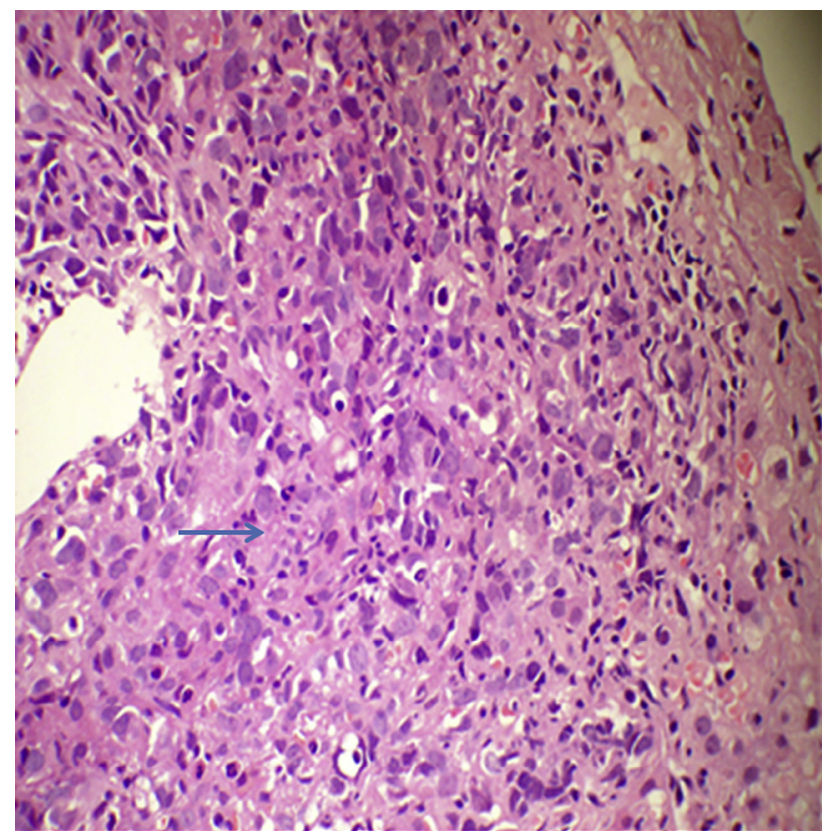

Figure 2 Liver biopsy showing infiltration by atypical lymphoid cells (arrow).

\section{CONFLICTS OF INTEREST}

All authors have none to declare.

\section{REFERENCES}

1. Engels EA, Pfeiffer RM, Landgren O, Moore RD. Immunologic and virologic predictors of AIDS-related non-Hodgkin lymphoma in the

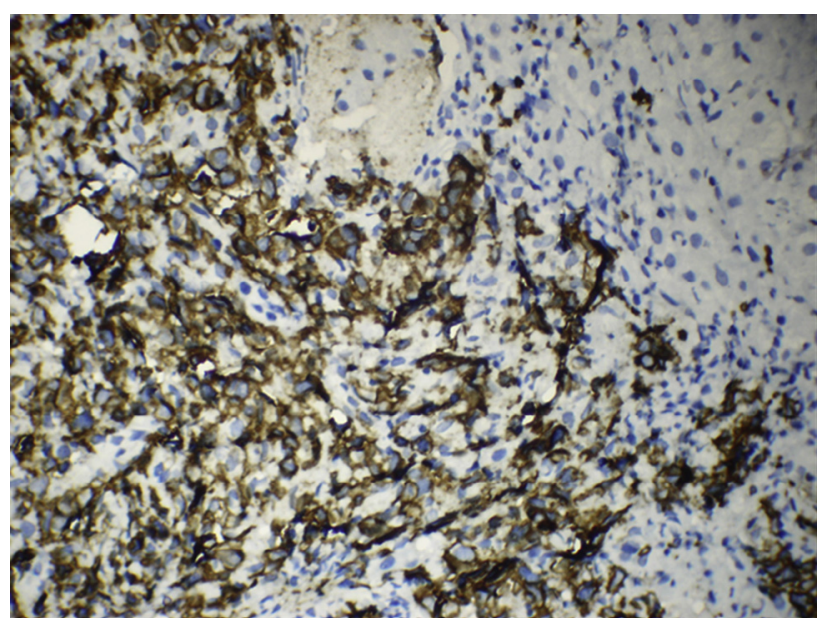

Figure 3 Strong immunopositivity of atypical lymphoid cells for B cell marker CD 20. $(\mathrm{IHC} \times 400)$.

highly active antiretroviral therapy era. J Acquir Immune Defic Syndr. 2010;54:78-84.

2. Gatselis NK, Dalekos GN. Primary hepatic lymphoma. J Gastroenterol Hepatol. 2011;26:210.

3. Lei KI. Primary non-Hodgkin' s lymphoma of the liver. Leuk Lymphoma. 1998;29:293-299.

4. Zafar MS, Aggarwal S, Bhalla S. Complete response to chemotherapy in primary hepatic lymphoma. I Cancer Res Ther. 2012;8:114-116. 